\title{
NON-TRADITIONAL STUDENTS, UNIVERSITY TRAJECTORIES, AND HIGHER EDUCATION INSTITUTIONS: A COMPARATIVE ANALYSIS OF FACE-TO-FACE AND ONLINE UNIVERSITIES
}

\author{
ALBERT SÁNCHEZ-GELABERT
}

\begin{abstract}
In recent decades, the number of students accessing higher education has grown, leading to a greater diversity of student profiles and modalities of studying. This means a new scenario among higher education institutions in which online universities are becoming increasingly relevant. The aim of this article is to explore how students' university trajectories differ according to age, gender, and university type at three Catalan universities $(\mathrm{N}=20,745)$. For this purpose, we carried out a sequence analysis to identify university trajectories and then compared them according to the study modality (face-to-face/online) and the student profile (traditionall non-traditional). The results show differences in university progression trajectories among non-traditional students according to the university type. In particular, there was a higher incidence of dropout at face-to-face universities among non-traditional students. In the case of online universities, in contrast, dropout was not a phenomenon exclusive to non-traditional students, with similar dropout rates among all students regardless of profile.
\end{abstract}

Keywords

university trajectories, non-traditional student, dropout, online university, longitudinal analysis 


\section{Introduction}

In recent decades, there has been a substantial increase in the number of students entering higher education, generalized across all higher education institutions (HEIs) and with the greatest increase in online and distance universities (Ashby et al., 2011). This differential growth has shown that online education is no longer peripheral or marginal, but is becoming increasingly central (Xiao, 2018). These trends highlight a new interrelationship in the higher education system where the boundaries between the two modalities are becoming increasingly blurred (Tait \& Mills, 1999).

A similar trend can be observed in the Catalan higher education system. Over the past 15 years, there has been an increase of more than $14 \%$ in the number of students accessing higher education in both face-to-face and online education. ${ }^{1}$ However, the increase in new students has been especially significant in the online modality $(+35.2 \%)$, which may represent the growing demand for flexibility among students. In this regard, online education can be an opportunity for non-traditional students who need to combine their studies with external responsibilities such as family or work commitments.

One of the main concerns with online education is the phenomenon of dropout and low retention rates (Lee \& Choi, 2011; Simpson, 2013). The data are conclusive in this regard, with a clear trend towards a higher rate of dropout among students in online universities than those in face-to-face institutions (Patterson \& McFadden, 2009; Xu \& Jaggars, 2014). In this context, the new centrality of online universities may be weakened if they fail to introduce measures to mitigate the high dropout rates and increase retention of the more numerous and heterogeneous new students.

Retention is one of the great challenges for higher education research given that it is consolidated as an indicator of efficiency and effectiveness. The challenge is even greater if we consider its potential consequences in terms of social equity. European policies in recent years have focused on increasing and expanding access to and participation in HEIs, especially among non-traditional students. It is now time to go further and introduce measures to increase the retention of students at a higher risk of dropping out.

Data from the University Pre-registration Office of the Inter-University Council of Catalonia and the Office of Planning and Quality of the Open University of Catalonia. 
Many researchers, however, have highlighted the complexity of analyzing dropout due to the interaction of a large number of factors, for both faceto-face and online universities (Grau-Valldosera \& Minguillón, 2014; Kehm et al., 2019; Lee \& Choi, 2011; Morgan \& Tam, 1999). The difficulties involved in balancing the university experience and external responsibilities including work and family, discontinuities in educational trajectories, differential paces and progress in studies, and managing stressful situations are among the reasons that add complexity to the phenomenon.

In response to this complexity, an increasing number of studies have been incorporating a longitudinal perspective that considers the university experience as a long and broad educational trajectory (Haas \& Hadjar, 2019; Robinson, 2004). In this regard, a longitudinal analysis of student trajectories enables us to consider the diversity of HEIs and the growing diversity of student profiles. At the same time, it provides an opportunity to explore the incidence of dropout among non-traditional students in different types of universities (face-to-face and online) compared to the rate for traditional students.

\section{Trajectories in higher education, non-traditional students, and university type}

A recent review of 44 empirical works on dropout in Europe evidenced a clear pattern with gender and dropout in higher education, concluding that dropout is clearly higher among men than women (Kehm et al., 2019). Empirical findings in other countries point in the same direction, showing that women's university trajectories are characterized by fewer interruptions and a greater likelihood of persistence and graduation (Denice, 2019; Goldrick-Rab, 2006).

In the specific case of online education, the research has not reached conclusive results. While some research has indicated that there is no significant association between gender and dropout rates (Patterson \& McFadden, 2009; Tello, 2007; Wojciechowski, 2004), other studies have pointed to a higher probability of dropout among men (Packham et al., 2004), and a greater likelihood of women continuing (Grau-Valldosera et al., 2019) and obtaining degrees in specific fields, particularly in those where they are a small minority (Callejo Gallego, 2001). In contrast, some research has suggested a pattern of higher dropout risk among women regardless of the type of studies undertaken or previous grades obtained (Stoessel et al., 2015).

Another structural variable that has been widely analyzed in relation to university dropout is age. As with the gender-dropout link, a review of empirical findings in Europe has shown a clear pattern: the younger a student 
is, the lower their risk of dropout is (Kehm et al., 2019). Again, the results for online education environments have not been entirely conclusive. Different research has found that older students have a higher (Wojciechowski, 2004) or lower (Stoessel et al., 2015) risk of dropping out. In contrast, other studies have concluded that the older a student is, the greater the probability that they will drop out is (Packham et al., 2004; Rodrigues de Oliveira et al., 2018). Lastly, there is also research that has concluded that there are no differences between different age groups (Tello, 2007; Willging \& Johnson, 2009).

In the case of master's students, some research has compared the effect of age considering the modality, online or face-to-face. The results showed a net effect from age after controlling for other variables (Patterson \& McFadden, 2009). In this regard, the general conclusion is that students who drop out are significantly older than their persistent counterparts.

However, some studies have found that structural variables, such as age and gender, have not shown predictive power for first-year college dropouts when other variables are included. Some authors have found that the effect of age on dropout disappears when the employment situation is taken into account (Gilardi \& Guglielmetti, 2011). The results indicate that the probability of dropping out is linked to the economic situation of the student, regardless of age, meaning that working students are more likely to drop out at any age.

In the Catalan context, some research has taken a similar approach and also included student performance (Sánchez-Gelabert \& Elias, 2017). In that study, a typology of students was constructed by combining their age and employment situation at the time of entering university. The results showed that non-traditional students (older and working) dropped out more frequently even when they were performing better than their traditional counterparts. Thus, the authors concluded that the probability of dropping out was higher among older students, regardless of employment status.

Evidence of the effect of age and work on dropout is particularly important in the case of online universities, given the specific profile of students there. Several empirical studies have shown that the probability of participating in online universities is higher among older students (Ortagus, 2017), students who combine their studies with a full-time job (Cavanaugh \& Jacquemin, 2015), and students with multiple responsibilities such as family and work (Sánchez-Gelabert et al., 2020).

This set of results highlights the importance of incorporating a perspective that addresses students' life cycle, including work experience and family responsibilities such as motherhood and caring for family members. Notably, approaches to the study of non-traditional students are broad and include an enormous diversity of characteristics (Treiniené, 2019). In addition to external responsibilities, some approaches have included students who 
are first-in-family students, adult learners, or delayed-entery students, among others. One of the most widely used indicators has traditionally been age, given that it is associated with certain characteristics of a student's life cycle. To this effect, age in general, and in particular the age of 25 , has become a commonly used indicator (Tilley, 2014) that allows for a more comprehensive approach to the experience of non-traditional students.

The importance of introducing this distinction into the analysis of educational phenomena is twofold. First, it is a growing reality in the higher education system. Second, and more importantly, the characteristics of non-traditional students differ from those of their traditional peers, the importance of which lies in the impact this has on different dimensions, such as entry motivations (Dos Santos, 2020; Sánchez-Gelabert et al., 2020), dedication to studies (Safford \& Stinton, 2016), experiences during university, and educational outcomes (Choi \& Park, 2018).

One of the most widely used performance indicators is university dropout. Some research has compared this indicator in students enrolled in faceto-face and online courses. The results showed that students received lower grades and were more likely to drop out of online courses than traditional face-to-face courses (Francis et al., 2019; Lundberg et al., 2008; Xu \& Jaggars, 2011, 2014). Some authors have stated that these differences may have been due to the issue of self-selection between the two types of courses (Lundberg et al., 2008). In this regard, additional research has deepened these results by introducing the characteristics of students. The main findings have been that adult online students (Francis et al., 2019) and specifically adult male online students (Glazier et al., 2020; Sproat, 2018) have displayed lower performance and higher dropout rates compared to adult face-to-face students and traditional age students.

\section{Analytical strategy}

\section{Objective and methodology}

The main objective of this paper is to explore how students' university trajectories differ according to their profile (traditional/non-traditional) and the type of university. With this objective in mind, the analytical strategy was divided into three steps. First, we carried out a longitudinal analysis of the trajectories of new students taking their profiles into account. Second, students' trajectories were compared at three universities, two face-to-face universities and one online university. Last, we explored the relationship between students' trajectories and profiles and whether this relationship varied according to the type of university. 
Three new access cohorts for a single year were analyzed to establish a comparative framework and control for the multiple changes that have occurred in the Spanish university system. Given that the years of completion at online universities are much higher than those at face-to-face institutions, the cohort of students who entered in 2009-10 was selected. For the online university, the trajectories were analyzed for 9 academic years (2009-10 to 2018-19), while for the face-to-face universities they were analyzed for the period between the 2009-10 and 2013-14 academic years.

\section{Data}

The data correspond to new undergraduate students (4-year programs) in the 2009-10 academic year at three Catalan universities $(N=20,745)$. The data come from annual student records and were provided by the information management offices of the three universities analyzed.

The Universitat Politècnica de Catalunya (UPC) is a public institution with a primarily technical orientation. Most of the students (97\% in 2009-10) were studying engineering and architecture $(n=3,262)$. The data come from the area of Planning, Quality, and Transversal Programs.

The Autonomous University of Barcelona (UAB) is a public university with a broad offer in terms of fields of study. The percentages of students in various fields of study during 2009-10 was as follows $(n=6,163): 50.7 \%$ in social and legal sciences, $17.8 \%$ in arts and humanities, $13.2 \%$ in sciences, $10.7 \%$ in health sciences, and $7.6 \%$ in engineering and architecture. The data come from the Office of Information and Documentation Management.

The Universitat Oberta de Catalunya (Open University of Catalonia, UOC) is a fully online university with the following distribution of enrolled students $(n=11,320)$ according to fields of study during 2009-10: social and legal sciences (47.5\%), architecture and engineering (24.6\%), health sciences $(19.0 \%)$, and arts and humanities $(8.9 \%)$. The data come from the Office of Planning and Quality.

\section{Variables and measurements}

\section{Non-traditional students}

Non-traditional students are considered to be those students over 25 years of age at the time of entering university. A new variable was also constructed by introducing sex to explore the interactions of the two factors. The resulting variable is coded as follows: $1=$ traditional male students (men up to 25 years old); 2 = non-traditional male students (men older than 25 years old); $3=$ traditional female students (women up to 25 years old); and $4=$ nontraditional female students (women older than 25 years old). 


\section{Students' trajectories: Analytical strategy}

A sequence analysis was carried out to categorize the university trajectories (sequences) according to their similarity to one another. Three educational statuses were differentiated for each year: $1=$ studying, 2 = not studying, $3=$ graduated. Optimal matching analysis provided a measure of the similarity (or dissimilarity) between sequences. Based on a calculation of the dissimilarities between sequences, a cluster analysis (Ward's method) in which sequences that are similar to one another are grouped together was conducted. The analysis used the TraMineR extension for sequence analysis of the $\mathrm{R}$ statistical package (Gabadinho et al., 2011).

Last, an analysis of the association between the typology of the trajectories and profiles was carried out by means of a Chi-squared test. The analysis of adjusted standardized residuals enabled us to identify the significant relationships between the students' trajectories and the typology of nontraditional students.

\section{Results}

\section{Student profile by university modality}

One consideration prior to analyzing the students' trajectories was the differences in the students' profiles in terms of the type of university and modality of study. One of the most distinctive elements of the institutions was the sex of the students. As can be seen in Table 1, 3 out of every 4 students in the cohort from the technical university were men (74.3\%). This percentage was reversed in the other face-to-face university (UAB), with $60 \%$ of them being women. In the case of the online university, the percentages of students of each sex are similar.

Another characteristic is that the Catalan face-to-face universities contained a greater number of young students. The average ages of new students at the UAB and the UPC were 20.1 and 21.7, respectively. In contrast, at the online university the students' age was more than 10 years higher, at around 33 . This differing age composition also reflects differences in the relative proportions of access routes. At the UAB (a face-to-face generalist university), nearly $70 \%$ of the students accessed the university through the traditional academic route (a bachelor's degree). At the UPC, the academic track was the route for almost half of the students (47.4\%). A distinctive feature of this university was the importance of students accessing its degree programs through higher-level vocational education and training (VET) $(20.6 \%)$ or with some previous university experience (31.3\%). Last, in the case of the online university (UOC), most of the students $(70 \%)$ had had previous university experience. 
Table 1

Students' socio-demographic profiles according to university type and study modality

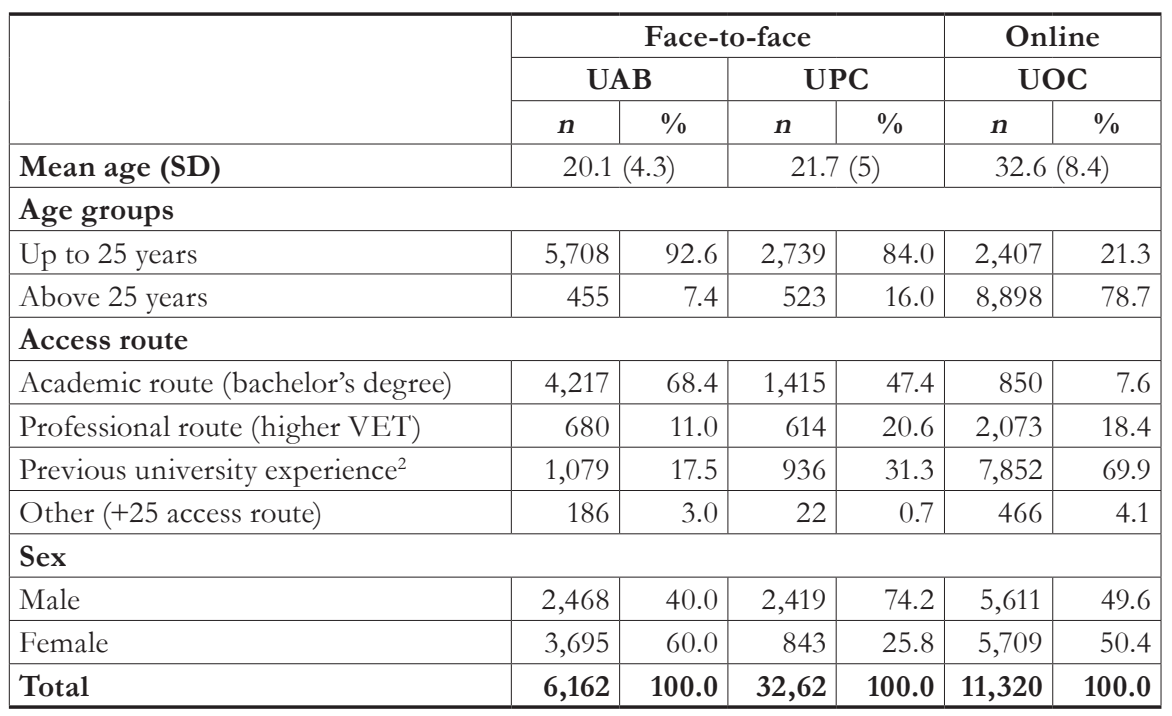

The importance of the student profiles and the learning context lay in the fact that these aspects had an impact on both the university experience and student outcomes. It is especially important to clarify whether there were any differences between the experiences of traditional and non-traditional students. As expected, the presence of non-traditional students varied according to the type of university and modality of study (Table 2). First, there was a majority presence of traditional students at the two face-to-face universities, and the UAB had the highest percentage of traditional students (92.6\%). Second, while the UAB had a higher percentage of traditional female students, the UPC had more traditional male students, representing almost 2 out of every 3 students (63.5\%). At the online university (UOC), a relatively large percentage of traditional female students stand out compared to their male counterparts.

Students with previous university experience, either with or without a degree. 
Table 2

Student profiles according to university type and study modality

\begin{tabular}{|l|r|r|r|r|r|r|r|}
\hline \multirow{2}{*}{} & \multicolumn{4}{|c|}{ Face-to-face } & \multicolumn{2}{c|}{ Online } \\
\cline { 2 - 7 } & \multicolumn{2}{|c|}{ UAB } & \multicolumn{2}{c|}{ UPC } & \multicolumn{2}{c|}{ UOC } \\
\cline { 2 - 7 } & $\mathbf{n}$ & \multicolumn{1}{|c}{$\boldsymbol{n}$} & $\boldsymbol{n}$ & $\mathbf{\%}$ & \multicolumn{1}{c|}{$\boldsymbol{~} \%$} \\
\hline Student typology & 3,456 & 56.1 & 668 & 20.5 & 1,373 & 12.1 \\
\hline Traditional female student & 2,252 & 36.5 & 2,071 & 63.5 & 1,034 & 9.1 \\
\hline Traditional male student & 239 & 3.9 & 175 & 5.4 & 4,331 & 38.3 \\
\hline Non-traditional female student & 216 & 3.5 & 348 & 10.7 & 4,567 & 40.4 \\
\hline Non-traditional male student & $\mathbf{6 , 1 6 2}$ & $\mathbf{1 0 0 . 0}$ & $\mathbf{3 , 2 6 2}$ & $\mathbf{1 0 0 . 0}$ & $\mathbf{1 1 , 3 2 0}$ & $\mathbf{1 0 0 . 0}$ \\
\hline Total & & & & &
\end{tabular}

Therefore, the face-to-face universities had more students with traditional profiles, that is, young students who entered through academic or professional routes and with no interruptions in their previous educational trajectories. Differences were observed when combining the students' age and sex, especially in the face-to-face universities. Traditional male students were predominant at the UPC, which is specialized in the fields of engineering and architecture, while the UAB predominantly had traditional female students.

\section{University trajectories by university type}

The sequence analysis enabled us to visualize the educational states of the cohort as a whole and their development from the time the students entered the universities. Figure 1 shows this development according to three educational statuses: studying, not studying, and having graduated. The first year was clearly central to retaining students in HEIs. This was especially significant at the online university, where $47.1 \%$ of the cohort was no longer studying in the year following entry. There were also interesting differences in face-to-face universities. Only $13.4 \%$ of the UAB students were no longer at the institution after the first year. At the end of the period analyzed, such students represented $25.2 \%$ of the total cohort. In the case of the UPC, the percentage of students who did not continue studying in the first year was $20.6 \%$, and two out of every three at the end of the period analyzed (29.3\%). If we look at the cross-sectional sequences according to student profile (Appendix A), differences between traditional and non-traditional students can be observed. Specifically, it is clear that the incidence of dropouts in the first year was higher among non-traditional students at face-to-face universities. 
Figure 1

Cross-sectional sequences of educational trajectories
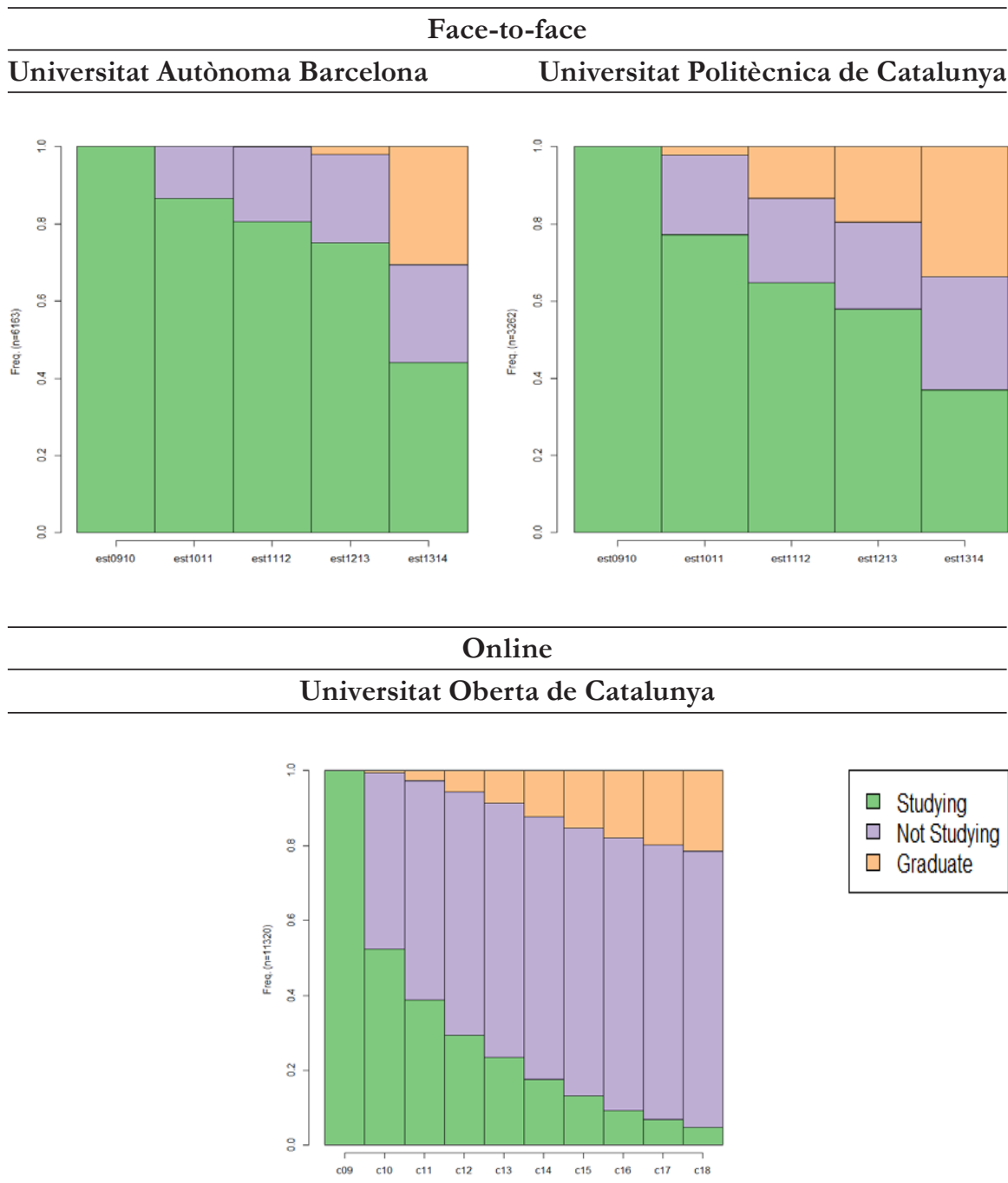

$\square$ Studying

$\square$ Not Studying

$\square$ Graduate

Another phenomenon observed is the different patterns for obtaining a degree among universities. In the case of the generalist face-to-face university (UAB), students began to graduate in the fourth year, the theoretical time it takes to earn a degree. In the case of the UPC, the graduation pattern differed slightly, with degree completion more spread out along the entire trajectory and starting from the third year. One possible explanation for these differences is the different student profiles at the two universities. In the case of the UPC, 
the presence of non-traditional students was greater than it was at the UAB, meaning that more students accessed higher education at the UPC with previous university experience, some of them having entered that university as a second opportunity to finish a degree they had already started. Meanwhile, the concentration of students with a traditional profile at the UAB may have resulted in a large presence of normative patterns.

It is also interesting to observe the pattern at the online university in relation to degree completion. A slow and steady increase can be seen, reaching $21.4 \%$ of the cohort in the last semester analyzed, 9 years after entry. Notably, $5 \%$ of the cohort continued to be enrolled after this period. These results are especially relevant given the large percentage of non-traditional students who studied at this online university. The introduction of a longitudinal perspective enables differences in student progression and graduation patterns according to institutional characteristics and learning environments to be highlighted. It also shows the importance of time and the duration of the trajectories in analyzing educational experiences, especially in the case of non-traditional students.

\section{Non-traditional students and university trajectories}

Based on the analysis of the probabilities of transition between each state over time (optimal matching), the students were grouped according to major patterns of progression (cluster analysis). Three patterns of university trajectories were identified: dropout,${ }^{3}$ persistence, ${ }^{4}$ and graduation.

One of the most notable differences between institutions regards dropout trajectories (Table 3). At the online university, almost 2 out of every 3 students in the cohort (61.0\%) had a dropout trajectory. In the case of the face-to-face universities, a much lower percentage of dropout trajectories was observed at around $23 \%$ of the cohort in each university. However, there were differences in the graduation trajectories between the two face-to-face universities. While about one-third of the UAB cohort graduated within a period of 5 years, this percentage dropped to $13.4 \%$ for the UPC cohort. Notably, around two-thirds of the cohort were on persistence paths in this university.

\footnotetext{
3 It should be noted that there can be multiple reasons for these dropout routes, such as transfer to other universities, change of modality, and closure of the educational registry.

$4 \quad$ Persistence trajectories refer to students who remain enrolled for several years after entering university and who, consequently, persisted in university beyond the first year. It should be borne in mind that these trajectories may correspond to students who, after several years at university, left without having obtained a degree.
} 
Table 3

Student pathways according to university type and study modality

\begin{tabular}{|c|c|c|c|c|c|c|}
\hline & \multicolumn{4}{|c|}{ Face-to-face } & \multirow{2}{*}{\multicolumn{2}{|c|}{$\begin{array}{c}\text { Online } \\
\text { UOC }\end{array}$}} \\
\hline & \multicolumn{2}{|c|}{ UAB } & \multicolumn{2}{|c|}{ UPC } & & \\
\hline & $n$ & $\%$ & $n$ & $\%$ & $n$ & $\%$ \\
\hline Dropout & 1,414 & $22.9 \%$ & 734 & $22.5 \%$ & 6.894 & $61.0 \%$ \\
\hline Graduation & 1,885 & $30.6 \%$ & 436 & $13.4 \%$ & 2,049 & $18.1 \%$ \\
\hline Persistence & 2,864 & $46.5 \%$ & 2,092 & $64.1 \%$ & 2,362 & $20.9 \%$ \\
\hline Total & 6,163 & $100 \%$ & 3,262 & $100 \%$ & 1,1305 & $100 \%$ \\
\hline
\end{tabular}

The main objective of this paper was to explore how students' university trajectories differed according to student profiles and university type. Based on an association analysis, it can be concluded that there was a significant relationship between the student profile and the type of university trajectories in the three universities analyzed $(p<0.05)$. By comparing the values for Cramér's $\mathrm{V}$, this association can be seen as more intense in the case of the face-to-face universities (UPC $=0.150, \mathrm{UAB}: 0.144$ ) than the online university $(\mathrm{UOC}=0.063)$.

An initial analysis of the data shows that there were differences in the trajectories of traditional students considering the type of university. More specifically, there was an association between traditional male students at face-to-face universities and persistence trajectories. Persistence was significantly higher among this group than among all students at both the UAB (52.4\% compared to $46.5 \%)$ and the UPC (68.3\% compared to $64.1 \%)$. At the UOC, in contrast, there was a significant relationship between this particular student profile and graduation trajectories: the percentage of traditional male students who graduated was slightly higher than the percentage for the cohort as a whole (23.2\% compared to $18.1 \%)$. In addition, higher dropout rates at the online university compared to the face-to-face universities were evident among both male and female traditional students. 


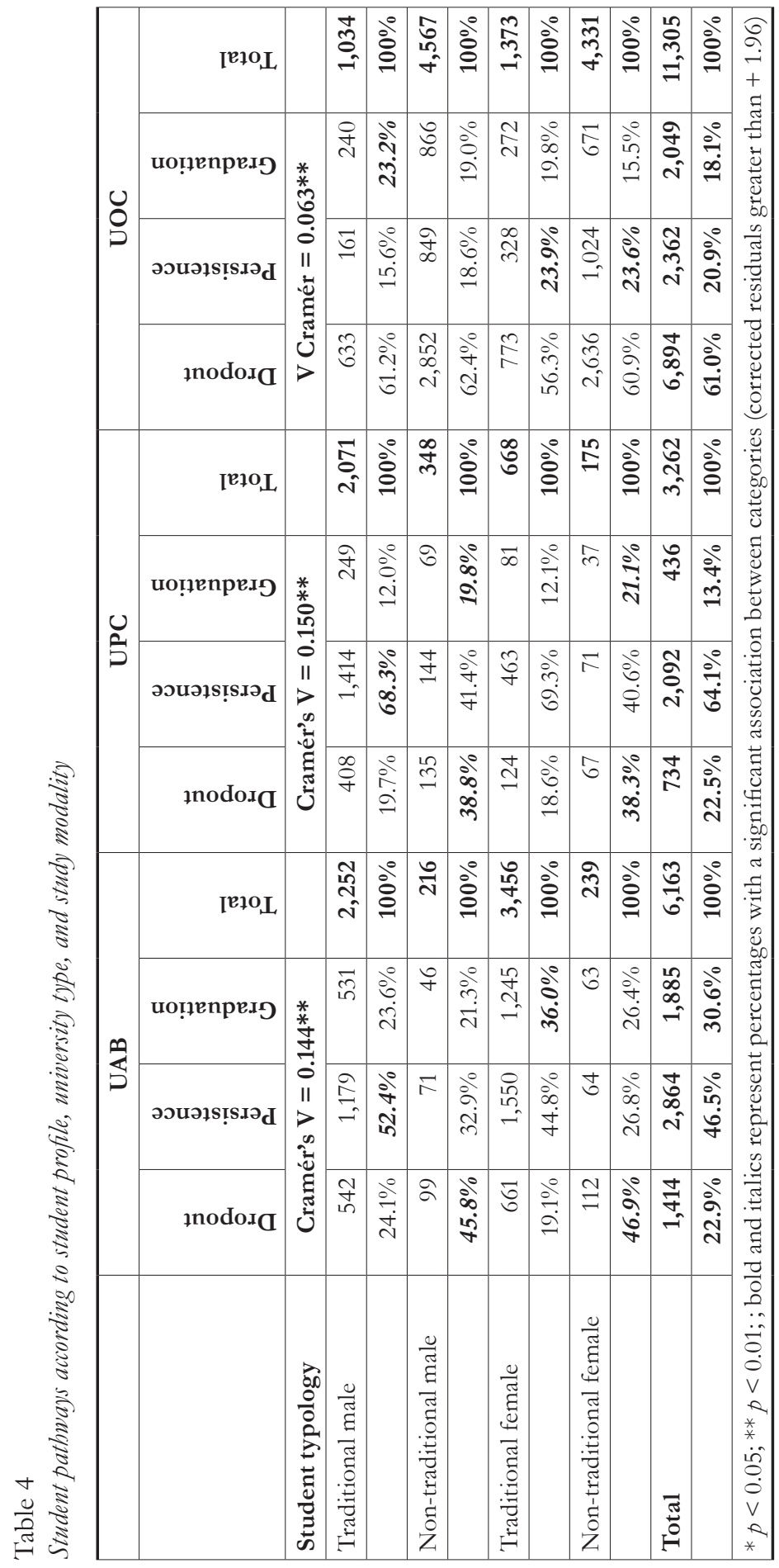


Last, the trajectories of traditional female students were analyzed. As seen in Table 4, there were no differences in the university trajectories of this group at the technical face-to-face university (UPC). It should be remembered, however, that this university had few traditional female students, representing 1 in 4 students in the cohort. The relationship varied depending on the type of university. At the UAB, traditional female students showed a significant association with graduation trajectories (36\% compared to $30.6 \%$ overall). At the UOC, the percentage of traditional female students in the persistence trajectories was significantly higher than the percentage for the general cohort $(23.9 \%$ and $20.9 \%$, respectively).

Focusing on the trajectories of non-traditional students also shows interesting results. Further analysis revealed a significant association between non-traditional students and dropout trajectories at face-to-face universities, regardless of gender. The percentage of dropout trajectories among nontraditional students at the UAB was around $46 \%$ for both men and women, while it was $22.9 \%$ for the cohort overall. This pattern also applied at the UPC. While the dropout trajectory for the entire cohort was around 23\%, for non-traditional students it was around $40 \%$, regardless of gender.

At the online university (UOC), however, the link between non-traditional students and dropout trajectories did not show a significant relationship. Although dropout rates were particularly high among non-traditional students (over $60 \%$ of the cohort), dropout rates were very similar for traditional male and female students (61.2\% and 56.3\%, respectively). In fact, a differential pattern was observed at online universities in relation to gender regardless of age. Both non-traditional and traditional female students showed a significant relationship with persistence trajectories at the online university.

\section{Conclusions}

Recent years have witnessed an increase in the complexity of the logic of access, participation, and completion in higher education. Not only has the number of students accessing tertiary education increased, especially in online modalities, but the student profile in relation to age, access routes, and responsibilities outside the university has also become more diverse. In this context, it is essential to explore how university trajectories, student profiles, and institution types are interrelated.

The first notable result of the analysis is that the profile of students varied substantially depending on the type and modality of the HEI. Regarding gender, differences were observed according to the type and modality of the university with an overrepresentation of male students at the more technical university, which is focused on architecture and engineering. There were also 
remarkable differences in university participation by university type and student profile. The presence of non-traditional students was much greater at the online university, where this profile represented about $80 \%$ of the student body. In contrast, the opposite trend was observed at the face-to-face universities, with an underrepresentation of this student profile. These results confirmed the self-selection of students into institutions pointed out by some authors (Lundberg et al., 2008; Tilley, 2014).

From a longitudinal perspective, patterns of progress and graduation at three HEIs were explored according to student profiles. Some interesting elements and trends were identified in relation to student trajectories, depending on the university type. First, the results are compelling in relation to university dropout. Dropout was more prevalent among students at the online university than at the face-to-face universities. At the online university, dropout trajectories represented $61.0 \%$ of the cohort, while at the face-to-face universities this percentage was around $23 \%$ of the cohort. These results confirmed the findings of an overwhelming trend toward dropout at online universities (Patterson \& McFadden, 2009) and a higher percentage of dropout at online universities compared to face-to-face universities (Francis et al., 2019; Xu \& Jaggars, 2014).

With regard to dropout, the importance of the first year at the three universities analyzed was confirmed. This phenomenon was particularly crucial at the online university, where almost half of the new students dropped out in the first year. Moreover, the online university showed a continuous and permanent dimension of dropout with constant incidence throughout the 9 years analyzed.

The main aim of the article was to analyze whether student trajectories differed according to student profile and university type. In this regard, we can outline some conclusions. First, the results showed an association between non-traditional students and dropout trajectories at the face-toface universities. The percentage of non-traditional students who did not continue their studies is almost double that of their traditional peers at the two face-to-face universities. The results from the online university differed substantially from the results from the face-to-face universities and showed relevant patterns. High dropout rates were observed at the online university, but this was not a phenomenon exclusive to non-traditional students. In fact, the percentages of students who dropped out were similar among the different student profiles. Therefore, we can conclude that dropout at online universities is not a phenomenon exclusive to a certain student profile but is a widespread phenomenon among the entire student body.

In the case of traditional female students, there were associations with graduation (UAB) and persistence (UOC) trajectories. These results are in line with other findings that have pointed to fewer discontinuities in trajectories 
and greater persistence and graduation among women (Denice, 2019; Goldrick-Rab, 2006). Further analysis showed that regardless of whether they were traditional students, female students had a specific relationship with the trajectories of educational persistence and continuity at the online university. Possible explanations for these results may be related to the increased presence of women and parents in distance education (Ortagus, 2017), the preponderance of women in health care tasks, and the possibility of combining these with more flexible education options. This highlights the need for constant dialogue to problematize the gendered nature of both care and learning (O'Shea et al., 2015).

These results confirmed some of the findings regarding student profiles and university modality. The statement that younger students had lower risks of dropping out (Kehm et al., 2019) was corroborated only in the case of the face-to-face universities. In the case of the online university, the risk of dropping out was similar among all student profiles. Similarly, the results support the main findings showing that online adult learners have higher dropout rates compared to face-to-face adult learners and traditional age students (Francis et al., 2019; Glazier et al., 2020).

One of the main limitations of this work is that the registration data did not enable analysis or exploration of the reasons and motivations for dropping out. In this regard, knowledge of the reasons for dropout must be deepened, especially among groups such as non-traditional students, who have high dropout rates at both face-to-face and online universities. In this regard, an important topic for further research is the reasons and motivations for entering university and how to face complex situations that involve combining studies with multiple responsibilities. Another of the elements to be analyzed in greater depth is the role of the HEI as either a facilitator and accompanier of the learning process or, on the contrary, a further obstacle in the complex combination of studies and other responsibilities outside the university. In this regard, the recent increase in enrollment in online education may be a response to a demand for greater flexibility from non-traditional students who have multiple responsibilities such as work, family, and so on. It should be noted that although online education has been seen as an opportunity to increase participation and social equity, high dropout rates are a major obstacle to achieving these goals.

These results pose major challenges for the future of HEIs and online education, considering recent trends such as increased participation in tertiary education, the growing importance of online education, and the increasing heterogeneity of students and their social and living conditions. On the one hand, face-to-face universities must respond more effectively to the new realities of university students and expand access and participation for nontraditional students. On the other hand, it is even more crucial to improve 
the retention of non-traditional students and decrease the high dropout rates. In the case of online universities, these should deepen the analysis of students' profiles and their needs, motivations, and reasons for entering university, in addition to the phenomenon of university dropout. Only if online universities succeed in increasing student retention rates can they consolidate themselves as second chance universities among non-traditional and under-represented students, thus contributing to increasing social equity.

\section{References}

Ashby, J., Sadera, W. A., \& McNary, S. W. (2011). Comparing student success between developmental math courses offered online, blended, and face-to-face. Journal of Interactive Online Learning, 10(3), 128-140.

Callejo, J. (2001). Estudio de cohorte de estudiantes de la UNED: una aproximación al análisis del abandono. Revista Iberoamericana de Educación a Distancia, 4(2), 33-70. https://doi. org/10.5944/ried.4.2.1179

Cavanaugh, J. K., \& Jacquemin, S. J. (2015). A large sample comparison of grade based student learning outcomes in online vs. face-to-face courses. Journal of Asynchronous Learning Network, 19(2). https://doi.org/10.24059/olj.v19i2.454

Choi, H. J., \& Park, J.-H. H. (2018). Testing a path-analytic model of adult dropout in online degree programs. Computers and Education, 116, 130-138. https://doi.org/10.1016/j. compedu.2017.09.005

Denice, P. (2019). Trajectories through postsecondary education and students' life course transitions. Social Science Research, 80,1-18. https://doi.org/10.1016/j.ssresearch.2019.02.005

Dos Santos, L. M. (2020). The motivation and experience of distance learning engineering programmes students: A study of non-traditional, returning, evening, and adult students. International Journal of Education and Practice, 8(1), 134-148. https://doi.org/10.18488/ journal.61.2020.81.134.148

Francis, M. K., Wormington, S. V., \& Hulleman, C. (2019). The costs of online learning: examining differences in motivation and academic outcomes in online and face-to-face community college developmental mathematics courses. Frontiers in Psychology, 10, 2054. https://doi.org/10.3389/fpsyg.2019.02054

Gabadinho, A., Ritschard, G., Mueller, N. S., \& Studer, M. (2011). Analyzing and visualizing state sequences in R with TraMineR. Journal of Statistical Software, 40(4), 1-37.

Gilardi, S., \& Guglielmetti, C. (2011). University life of non-traditional students: engagement styles and impact on attrition. The Journal of Higher Education, 82(1), 33-53. https://doi.org /10.1080/00221546.2011.11779084

Glazier, R. A., Hamann, K., Pollock, P. H., \& Wilson, B. M. (2020). Age, gender, and student success: mixing face-to-face and online courses in political science. Journal of Political Science Education, 16(2), 142-157. https://doi.org/10.1080/15512169.2018.1515636

Goldrick-Rab, S. (2006). Following their every move: An investigation of social-class differences in college pathways. Sociology of Education, 79(1), 67-79. https://doi. org $/ 10.1177 / 003804070607900104$ 
Grau-Valldosera, J., \& Minguillón, J. (2014). Rethinking dropout in online higher education: The case of the Universitat Oberta de Catalunya. International Review of Research in Open and Distance Learning, 15(1), 290-308. https://doi.org/10.19173/irrodl.v15i1.1628

Grau-Valldosera, J., Minguillón, J., \& Blasco-Moreno, A. (2019). Returning after taking a break in online distance higher education: from intention to effective re-enrollment. Interactive Learning Environments, 27(3), 307-323. https://doi.org/10.1080/10494820.2018.1 470986

Haas, C., \& Hadjar, A. (2019). Students' trajectories through higher education: a review of quantitative research. Higher Education, 79(6), 1099-1118. https://doi.org/10.1007/s10734019-00458-5

Kehm, B., Larsen, M., \& Sommersel, H. (2019). Student dropout from universities in Europe: A review of empirical literature. Hungarian Educational Research Journal, 9(2), 147-164. https:// doi.org/10.1556/063.9.2019.1.18

Lee, Y., \& Choi, J. (2011). A review of online course dropout research: Implications for practice and future research. Educational Technology Research and Development, 59(5), 593-618. https://doi.org/10.1007/s11423-010-9177-y

Lundberg, J., Castillo Merino, D., \& Dahmani, M. (2008). Do online students perform better than face-to-face students? Reflections and a short review of some empirical findings. RUSC. Universities and Knowledge Society Journal, 5(1). https://doi.org/10.7238/rusc.v5i1.326

Morgan, C. K., \& Tam, M. (1999). Unravelling the complexities of distance education student attrition. Distance Education, 20(1), 96-108. https://doi.org/10.1080/0158791990200108

O'Shea, S. E., Stone, C., \& Delahunty, J. (2015). "I 'feel' like I am at university even though I am online". Exploring how students narrate their engagement with higher education institutions in an online learning environment. Distance Education, 36(1), 41-58. https:// doi.org/10.1080/01587919.205.1019970

Ortagus, J. C. (2017). From the periphery to prominence: An examination of the changing profile of online students in American higher education. The Internet and Higher Education, 32, 47-57. https://doi.org/10.1016/J.IHEDUC.2016.09.002

Packham, G., Jones, P., Miller, C., \& Thomas, B. (2004). E-learning and retention: key factors influencing student withdrawal. Education + Training, 46(6/7), 335-342. https://doi. org $/ 10.1108 / 00400910410555240$

Patterson, B., \& McFadden, C. (2009). Attrition in online and campus degree programs. Online Journal of Distance Learning Administration, 12(2). https://eric.ed.gov/?id=EJ869274

Robinson, R. A. (2004). Pathways to completion: Patterns of progression through a university degree. HigherEducation, 47(1), 1-20. https://doi.org/10.1023/B:HIGH.0000009803.70418.9c

Rodrigues de Oliveira, P., Aparecida Oesterreich, S., \& Luci de Almeida, V. (2018). School dropout in graduate distance education: evidence from a study in the interior of Brazil. Educação e Pesquisa, 44, 1-20. https://doi.org/10.1590/s1678-4634201708165786

Safford, K., \& Stinton, J. (2016). Barriers to blended digital distance vocational learning for non-traditional students. British Journal of Educational Technology, 47(1), 135-150. https://doi. org/10.1111/bjet.12222

Sánchez-Gelabert, A., \& Elias, M. (2017). Los estudiantes universitarios no tradicionales y el abandono de los estudios. Estudios Sobre Educación, 32(0), 27-48. https://doi. org/10.15581/004.32.27-48

Sánchez-Gelabert, A., Valente, R., \& Duart, J. M. (2020). Profiles of online students and the impact of their university experience. International Review of Research in Open and Distributed Learning, 21(3), 230-249. https://doi.org/10.19173/irrodl.v21i3.4784 
Simpson, O. (2013). Student retention in distance education: are we failing our students? Open Learning, 28(2), 105-119. https://doi.org/10.1080/02680513.2013.847363

Sproat, W. (2018). Success rates of second semester anatomy students in online and on-ground classes at a Community College in East Tennessee. [Dissertation, East Tennessee State University]. Electronic theses and dissertations of ETSU. https://dc.etsu.edu/etd/3371

Stoessel, K., Ihme, T. A., Barbarino, M.-L., Fisseler, B., \& Stürmer, S. (2015). Sociodemographic diversity and distance education: Who drops out from academic programs and why? Research in Higher Education, 56(3), 228-246. https://doi.org/10.1007/s11162-014-9343-x

Tait, A., \& Mills, R. (1999). The convergence of distance and conventional education. Patterns of flexibility for the individual learner. Routledge.

Tello, S. F. (2007). An analysis of student persistence in online education. International Journal of Information and Communication Technology Education, 3(3), 47-62. https://doi.org/10.4018/ jicte. 2007070105

Tilley, B. P. (2014). What makes a student non-traditional? A comparison of students over and under age 25 in online, accelerated psychology courses. Psychology Learning \& Teaching, 13(2), 95-106. https://doi.org/10.2304/plat.2014.13.2.95

Treiniené, D. (2019). The concept of nontraditional student. Vocational Training: Research And Realities, 28(1), 40-60. https://doi.org/10.2478/vtrr-2017-0004

Willging, P. A., \& Johnson, S. D. (2009). Factors that influence students' decision to dropout of online courses. Journal of Asynchronous Learning Networks, 13(3). https://eric.ed. gov/?id=EJ862360

Wojciechowski, A. (2004). The relationship between student characteristics and success in an online business course at West Shore Community College. [Dissertation, Western Michigan University]. Scholar Works at WMU. https://scholarworks.wmich.edu/cgi/viewcontent. c gi ?article $=2152 \&$ contex $=$ dissertations

Xiao, J. (2018). On the margins or at the center? Distance education in higher education. Distance Education, 39(2), 259-274. https://doi.org/10.1080/01587919.2018.1429213

Xu, D., \& Jaggars, S. S. (2011). Online and bybrid course enrollment and performance in Washington State Community and Technical Colleges. Community College Research Centre, Teachers College, Columbia University. https://ccrc.tc.columbia.edu/publications/online-hybrid-courseswashington.html

Xu, D., \& Jaggars, S. S. (2014). Performance gaps between online and face-to-face courses: Differences across types of students and academic subject areas. The Journal of Higher Education, 85(5), 633-659. https://doi.org/10.1080/00221546.2014.11777343

\section{Corresponding author}

Albert Sánchez-Gelabert

Education and Work Research Group (GRET), Department of Sociology, Universitat Autònoma de Barcelona, Barcelona, Spain

E-mail: albert.sanchez@uab.cat 


\section{Appendix A}

Cross-sectional sequences according to student profile

$1=$ Traditional male student, $2=$ Non-traditional male student, $3=$ Traditional female student, 4 = Non-traditional female student

\section{UAB}
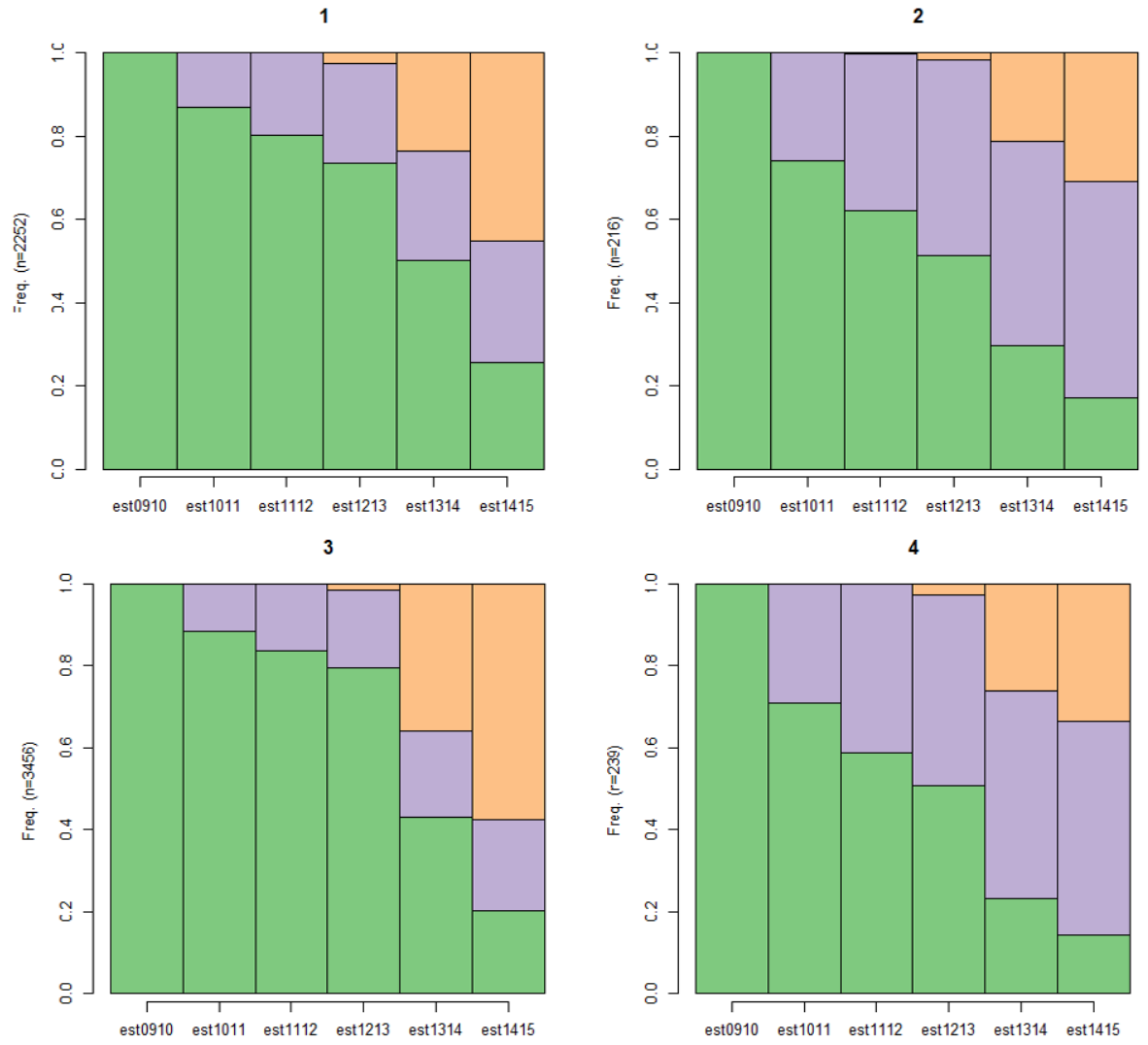


\section{UPC}

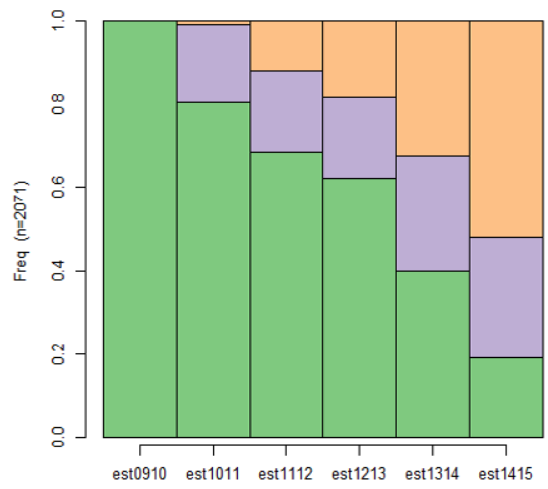

3

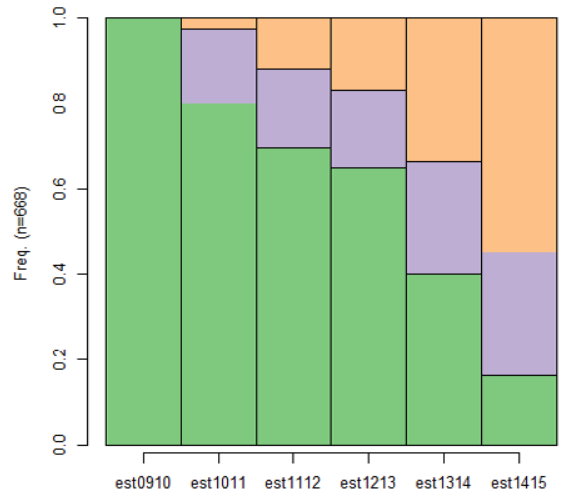

2

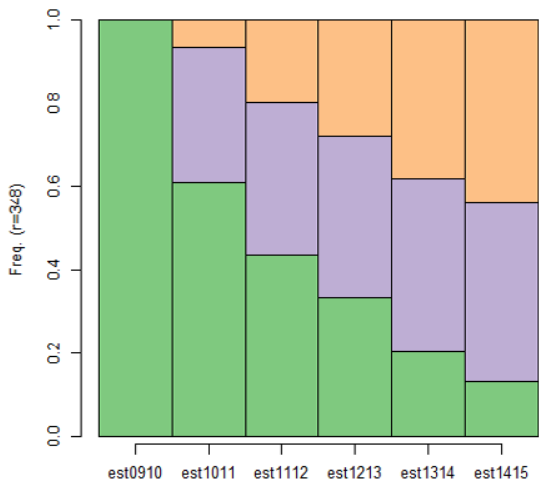

4

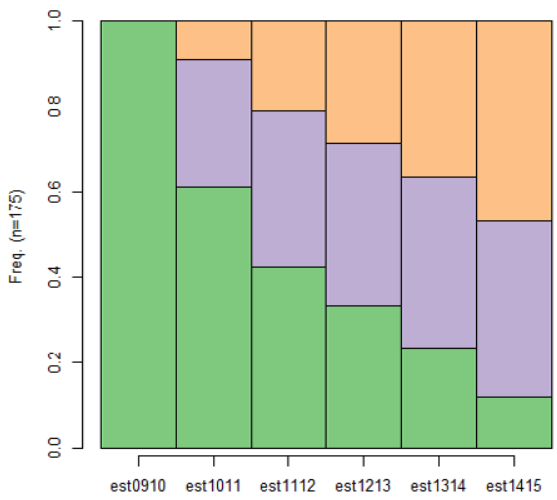




\section{UOC}
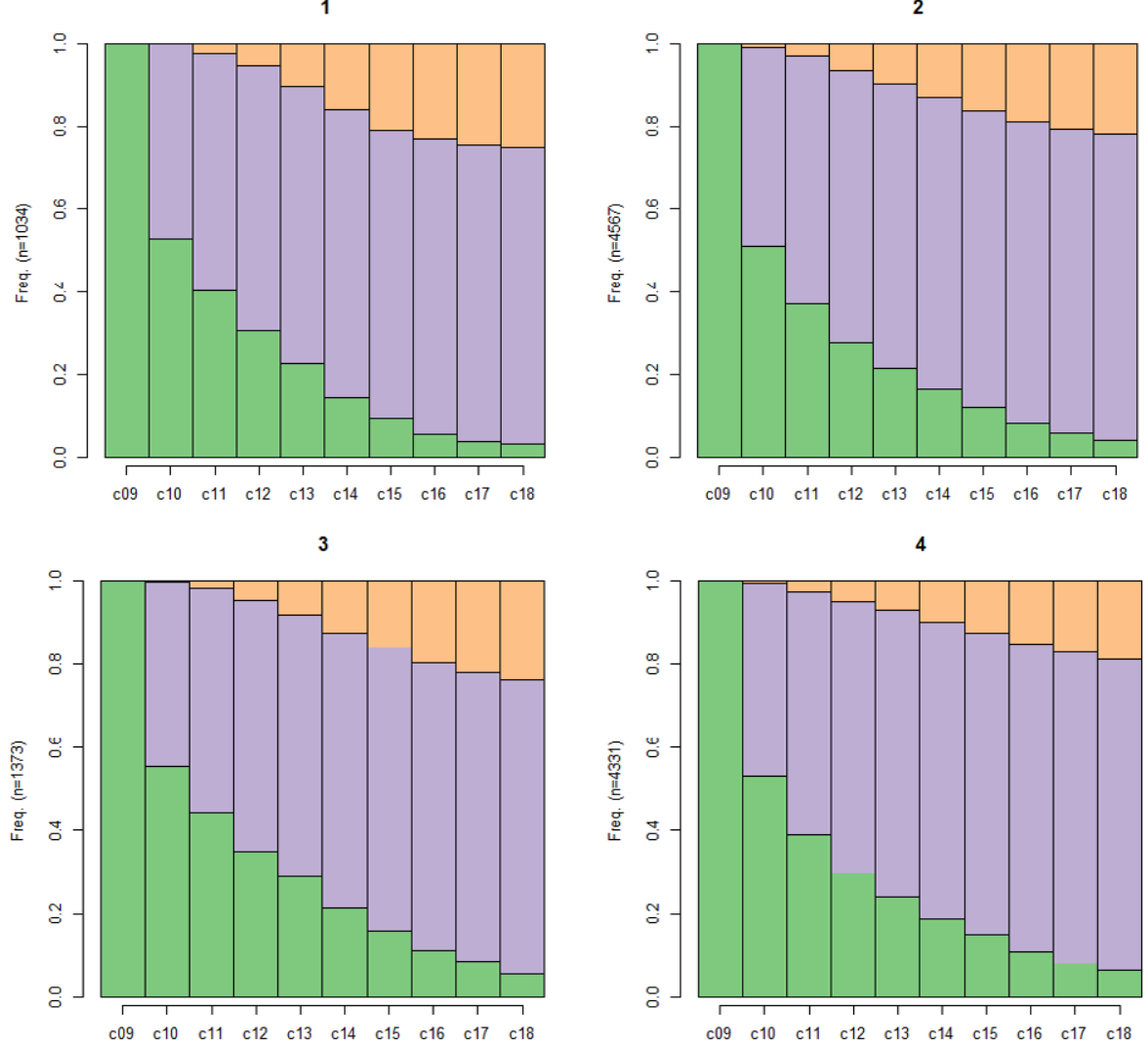